\title{
LOOP HEAT PIPES WITH A STEAM JET PUMP
}

\section{Kiseev and O. Sazhin}

Some configurations of cooling systems based on two-phase loops with control of the flow rate of the liquid and steam in them as well as experimental data obtained with these systems are presented. A model of an ejector-assisted loop heat pipe has been developed, and the results of calculations with it were compared with the corresponding experimental data.

Keywords: heat transfer device, two-phase loop, steam jet condensation, steam jet pump, ejector-assisted loop heat pipe.

Introduction. A steam jet pump (SJP) is a simple mechanical device designed for pumping a liquid, a gas, or a slurry in industrial processes. Despite the long history of use of such pumps, an accurate explanation of the physical processes occurring in them remains a subject of current research on simulation of two-phase flows. A SJP comprises a convergentdivergent nozzle, in which a liquid supplied to the pump is contained, a mixing section that can be called the SJP heart with a very complex hydrodynamics of the two-phase flow in it, and a diffuser that serves to increase the pressure of the liquid at the SJP exit (Fig. 1). In the SJP, a steam moving through the convergent-divergent nozzle is accelerated to a sonic or a supersonic velocity to create a negative pressure beyond the nozzle exit. As a result, the liquid being pumped is entrained and mixed with the motive fluid (steam), and the transfer of mass, momentum and heat from the motive fluid to the entrained liquid aids in accelerating the liquid flow.

Steam jet pumps have been investigated by many researchers both experimentally and computationally for improving their operational characteristics [1], especially those concerning the cooling of a high-temperature fluid or the heating of a lowtemperature fluid in them [2] for the purpose of using such a fluid in heating systems [3] and in the water supply systems of advanced nuclear reactors [4-9]. The majority of the recent investigations on steam ejection technologies were concentrated on the internal heat exchange in a steam jet pump and on the flash tank cycles in it [10]; however, these technologies have not been clearly defined as yet.

At present, heat-transfer devices based on two-phase loops (TPL), such as loop heat pipes (LHP) [11-15] and loop thermosyphons [16], are used in different space-based [17, 18] and earth-based [19] technologies. Among them, of particular importance are TPL devices with circulating steam and liquid flows, especially those based on loop heat pipes with an ejector condenser (ELHP) in which a SJP is a key element [20,21]. The condensation of a steam in an ELHP and the use of it in the ELHP ejector condenser for the provision of liquid circulation and heat transfer in it at a pressure lower than $100 \mathrm{kPa}$ call for additional investigations. An understanding of the indicated processes can be useful for the development of capillary pumpbased heat transfer devices with a high resistance to the unfavorable acceleration of the liquid flow in them.

The heat transfer in an ELHP is realized in the following way. The steam generated in the evaporator of the ELHP flows through its nozzle and enters the ELHP ejector condenser, in whose small cavity it is condensed and mixed with the liquid supplied continuously into the ELHP. As a result of the energy exchange between the steam and the liquid, the thermal and kinetic energies of the steam are converted into the potential energy forming a hydraulic head (a pressure difference between the liquid inlet and the steam nozzle exit (Fig. 1). This pressure difference forces the working liquid to circulate in the closed loop. The circulation of the liquid is determined by its ejection coefficient or the circulation flow multiplicity $U$ representing the ratio between the mass flow rate of the circulating liquid $\dot{m}_{\text {liq }}$ and the mass flow rate of the steam $\dot{m}_{\mathrm{v}}$. The ejection coefficient of the liquid can be calculated by its heat balance equation $\dot{m}_{\mathrm{v}} h_{\text {liq,v }}=\dot{m}_{\text {liq }} c_{\text {liq }}\left(T_{\text {liq,out }}-T_{\text {liq,inp }}\right)$ where $T_{\text {liq,inp }}$ and $T_{\text {liq,out }}$ are the temperatures of the liquid at the inlet of the SJP and the liquid at its outlet (exit), respectively. The heat transfer through a desired distance is provided by a heat exchanger (heat sink) installed in the loop. Thus, the circulation

Institute of Natural Science and Mathematics, Ural Federal University, 51 Lenin Ave., Ekaterinburg, 620000, Russia; email: Valery.Kiseev@urfu.ru. Published in Inzhenerno-Fizicheskii Zhurnal, Vol. 93, No. 2, pp. 722-731, May-June, 2020. Original article submitted December 7, 2018. 


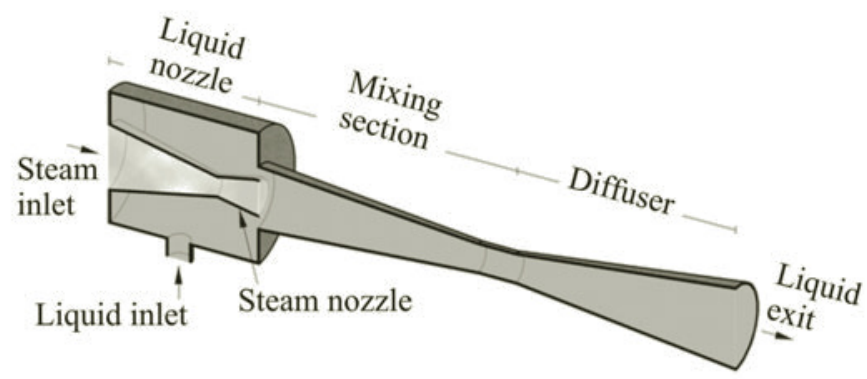

Fig. 1. Diagram of a steam jet pump.

of the working liquid in the ELHP proceeds with a maximum utilization of the kinetic and thermal energies of the submerged steam jet.

In the present work, a novel technique has been developed for investigating the condensation of a steam in the ejector of a TPL based on a capillary pump, and it has been realized with the use of a special hardware and field tests. The aim of this work is to determine the performance of the indicated TPL depending on the rates of the heat flows at its inlet and outlet, the orientation of the TPL, and its operational characteristics under the conditions of unfavorable acceleration of the liquid flow in it.

Experimental. Figure 2 shows a scheme of an ELHP comprising an evaporator (at the top), a heat exchanger (at the bottom), and a loop pipe providing the circulation of the working liquid between them. The length of this loop is sufficient for the transfer of heat through a desired distance. An ejector condenser can be positioned outside the evaporator (ELHPE) or inside it (ELHPI). The wicks used in the investigations were made of porous nickel and titanium with pores of average diameter 1 and $10 \mu \mathrm{m}$, respectively (Fig. 3). They served as a capillary pump joining the evaporator, the ejector condenser, and the heat exchanger in a closed loop of arbitrary configuration. This loop comprized steam channels having smooth walls with steam escape ducts, a nozzle of inner diameter $1.4 \mathrm{~mm}$, and liquid channels of inner diameter $2 \mathrm{~mm}$. Water was used as a working liquid. The LHP, the steam and water nozzles, the mixing section, and the diffuser were made of a stainless steel and represented separate parts connected by an argon welding. The maximum flow rate of the liquid in the capillary pump was $0.79 \mathrm{~kg} / \mathrm{h}$ at a heat load $Q=500 \mathrm{~W}$, and the maximum pressure in it was 0.70 bar. During an experiment, this pump continuously supplied a saturated steam into the ELHP, the temperature within which was measured by T-type copper and constantan thermocouples and was recorded by am OWEN data acquisition system. Inside the SJP, the steam and water came into direct contact with each other, and heat, mass, and momentum were transferred between them. The local hydrodynamics of the liquid flow in the ELHP is substantially determined by the geometry of the mixing section of the SJP. The physical parameters of the steam and water in the SJP and its geometric characteristics were as follows: inlet steam pressure 20-70 kPA, inlet steam temperature 323-363 K, inlet water temperature 293-323 K, steam nozzle outlet diameter $1.4 \mathrm{~mm}$, water nozzle outlet diameter $2.7 \mathrm{~mm}$, mixing section neck diameter $2 \mathrm{~mm}$, diffuser outlet diameter $3 \mathrm{~mm}$, steam nozzle length $10 \mathrm{~mm}$, mixing section length $10 \mathrm{~mm}$, diffuser length $15 \mathrm{~mm}$, and total length $35 \mathrm{~mm}$.

Results of Experiments. The operational characteristics of an ELHPE with a nickel wick, having an unfavorable orientation (the condenser and evaporator are positioned vertically, $\varphi=90^{\circ}$ ), were measured under different conditions of cooling the water in it. The characteristics of an ELHPI No. 1 with a titanium wick, having an unfavorable orientation $\left(\varphi=90^{\circ}\right)$, were measured at an acceleration of the liquid flow in it as high as $9 g$ with the use of a centrifuge comprising a rotation axis with a location for a heat pipe (Fig. 4). The influence of an increase in the effective heat transfer distance from 1 to $3 \mathrm{~m}$ in an ELHP on its performance characteristics $T=f(Q)$ was investigated for ELHPI No. 2 with a nickel wick, having an unfavorable orientation $\left(\varphi=90^{\circ}\right)$. It was established that the indicated increase leads to an increase in the resistance to the circulation of the liquid in the loop. The heat exchangers in ELHPI No.1 and ELHPI No. 2 were cooled by a water with a temperature of $20-40^{\circ} \mathrm{C}$ and a flow rate of 80 liter $/ \mathrm{h}$.

Figure 5 shows the dependences of the temperatures at the reference points A-E in the ELHPE with a nickel wick, having an unfavorable orientation, and the ejection coefficient of the liquid in it on the heat flow and the heat load at the heat input under different cooling conditions. Figure 6 presents the operational characteristics of ELHPI No.1 at liquid flow accelerations of $1 g$ and $9 g$, and the change in the operational characteristics of ELHPEI No. 2 with increase in the effective heat transfer distance in it from 1 to $3 \mathrm{~m}$. The results presented in this figure have been obtained for the most unfavorable orientation $\left(\varphi=90^{\circ}\right)$ of ELHPI No. 1 and ELHPEI No. 2. Note that the reference temperatures at $\varphi=0^{\circ}$ and $\varphi=-90^{\circ}$ are 

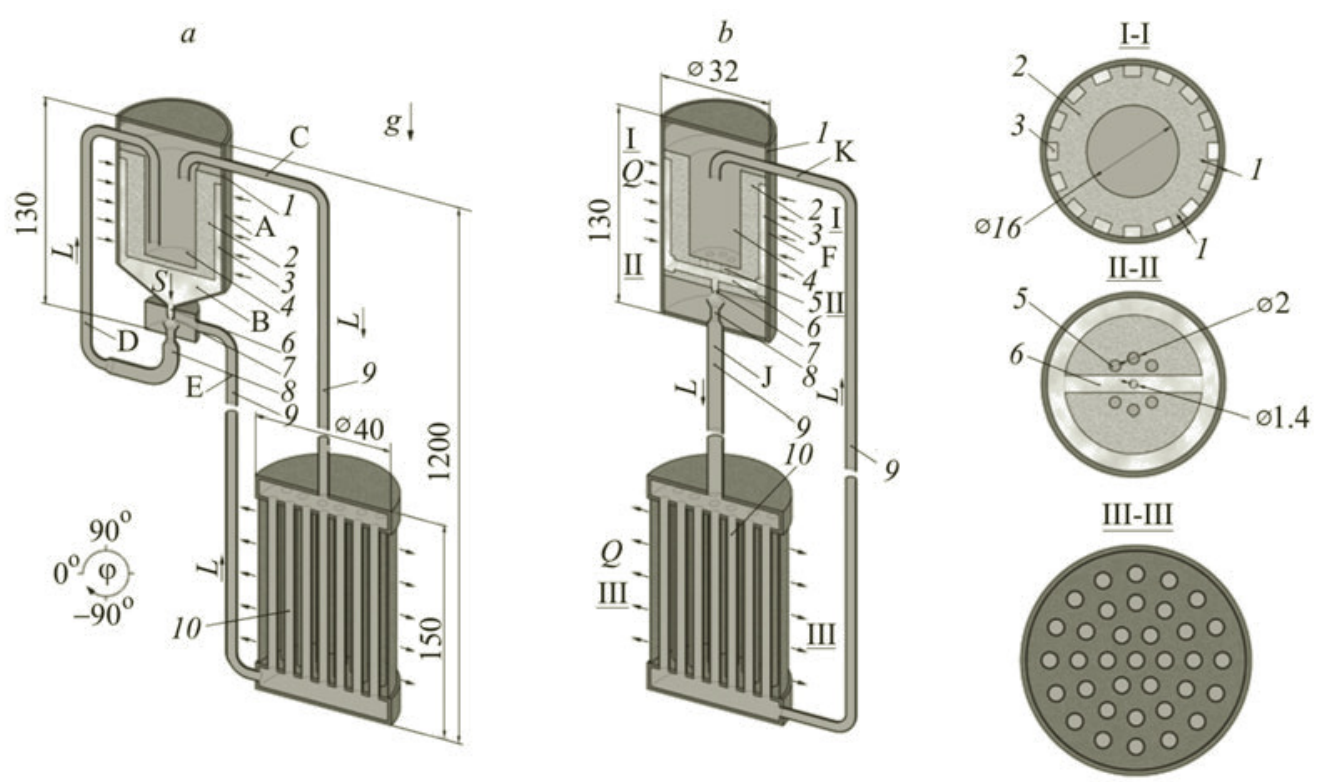

Fig. 2. Experimental ELHPE (a) and ELHPI (b): 1) evaporator; 2) wick; 3) steam escape ducts; 4) compensation cavity; 5) liquid channels; 6) steam collector; 7) injector nozzle; 8) mixing section and diffuser; 9) liquid line; 10) heat exchanger (heat sink); A, B, C, D, $\mathrm{E}, \mathrm{F}$, and $\mathrm{K}$ are reference points for temperature measurements.
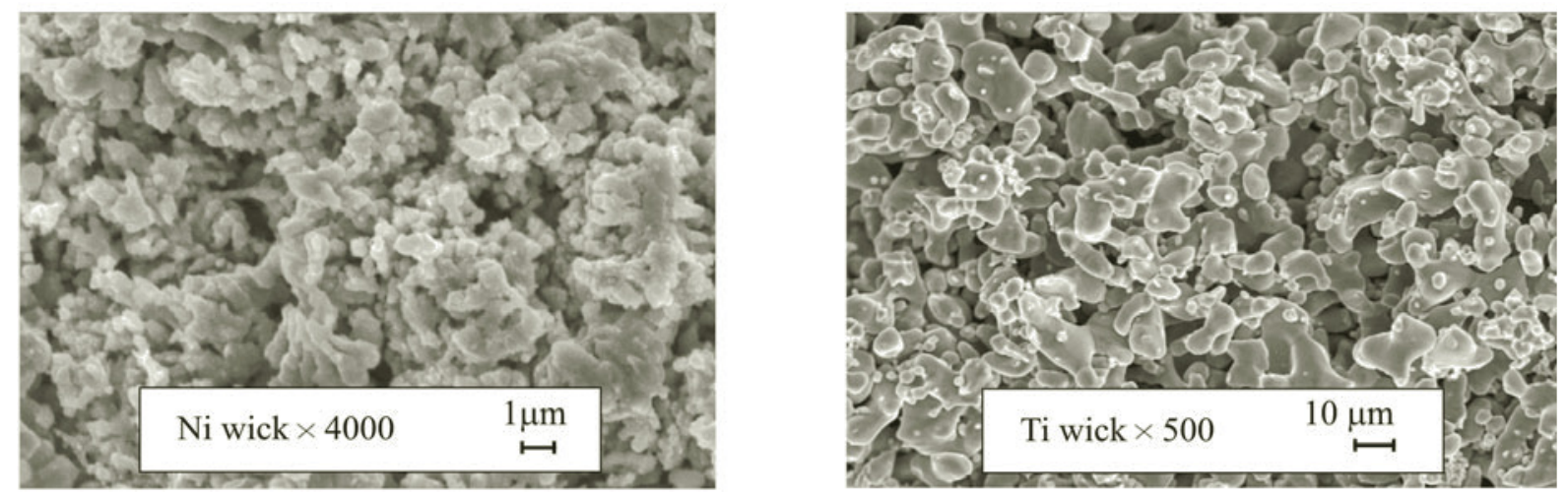

Fig. 3. Electron microscope scans of porous wicks used in the experiments.

lower by $5-10 \%$ than those at $\varphi=+90^{\circ}$. It is seen from Fig. 6 that the nine-fold increase in the acceleration of the liquid flow in ELHPI No.1 (Fig. 6a) and the three-fold increase in the heat transfer distance in ELHPI No. 2 (Fig. 6b) weakly influence the temperature of the liquid in them but markedly change their ejection coefficient. The indicated changes are caused by the small uncompensated columns in the steam escape ducts and in the ejector nozzle, and they increase the minimum heat load at the start-up of an ELHPI. The temperature of the liquid in an ELHPI and its ejection coefficient, presented in Figs. 5 and 6, were measured at its minimum start-up heat load. It should be noted that the start-up of an ELHPI depends on the temperature of the liquid entering the ejector. As this temperature increases to $40-50^{\circ} \mathrm{C}$, the operation of the ejector becomes impossible since the steam leaving the steam nozzle cannot be condensed fully. This effect is explained by the fact that the ejector has fixed sizes. Therefore, to make the operation of the ejector possible, it is necessary to cool the liquid at its inlet to $25-30^{\circ} \mathrm{C}$.

Computational Model. The capillary structure (CS) of an ELHP can be improved by optimizing its effective radius with account of the pressure drops at all the ELHP elements [15]. The capillary limit of the ELHP is equal to

$$
\Delta P_{\sigma, \max }=\frac{2 \sigma\left(T_{\mathrm{v}}\right)}{r_{\mathrm{eff}}},
$$




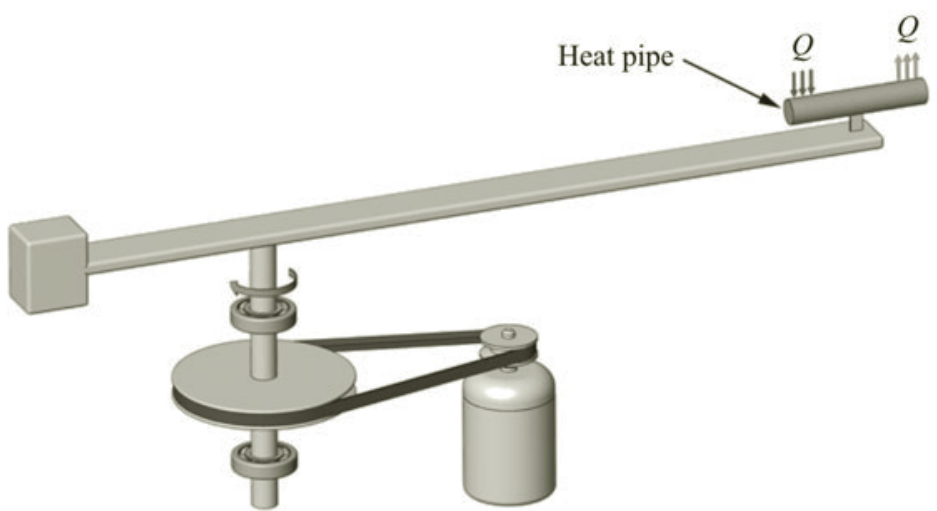

Fig. 4. Centrifuge with a heat pipe installed on it.
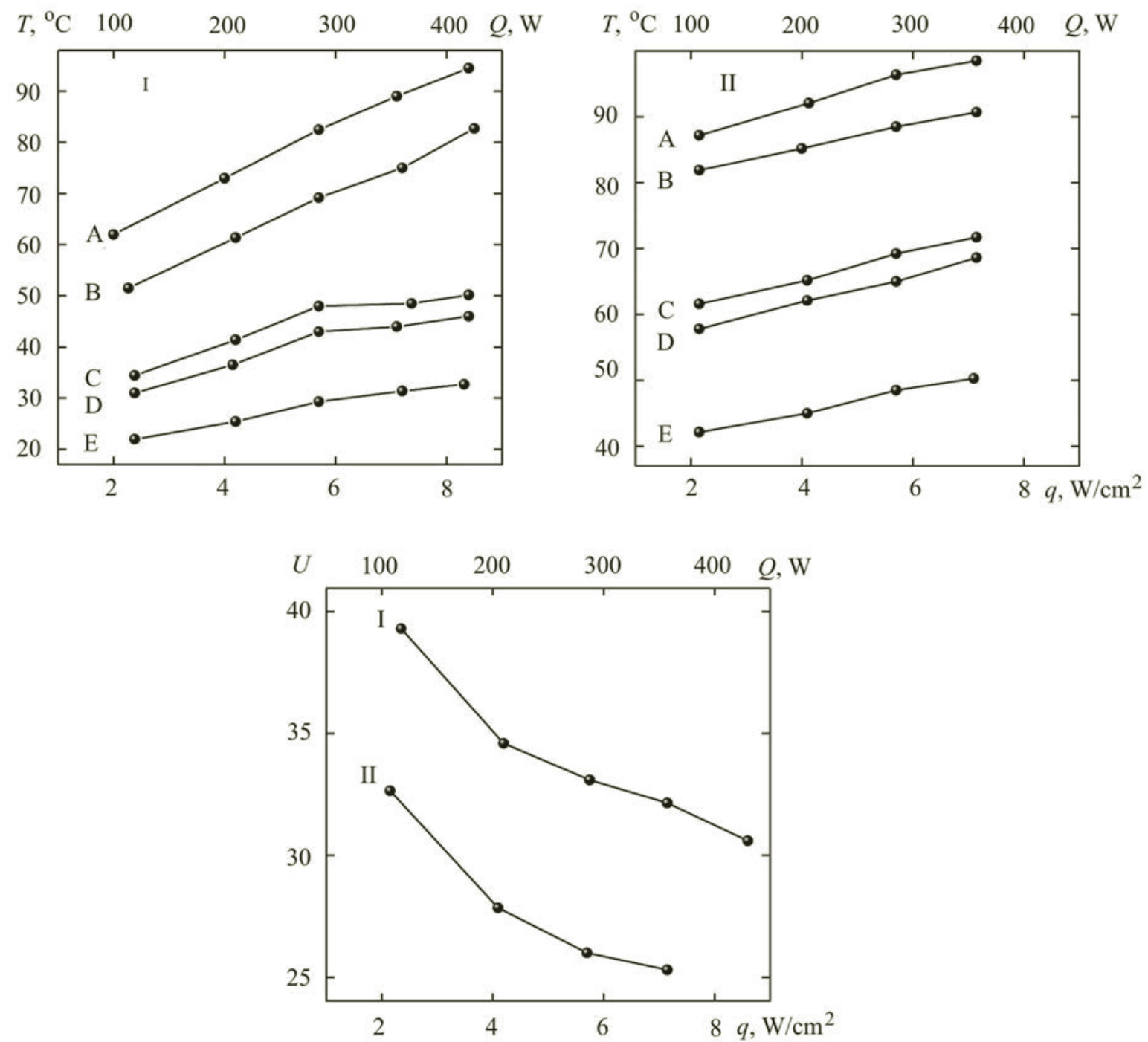

Fig. 5. Dependence of the temperatures at the reference points A-E inside the ELHPE with a nickel wick and an unfavorable orientation $\left(\varphi=90^{\circ}\right)$ on the power density of the heat flow in it and the heat load at its inlet under different cooling conditions: I) $T_{\mathrm{amb}}=20^{\circ} \mathrm{C}, T_{\text {c.w }}=20^{\circ} \mathrm{C}, \dot{m}_{\text {c.w }}=80 \mathrm{~L} / \mathrm{h}$; II) $20,40,80$. 
$a$

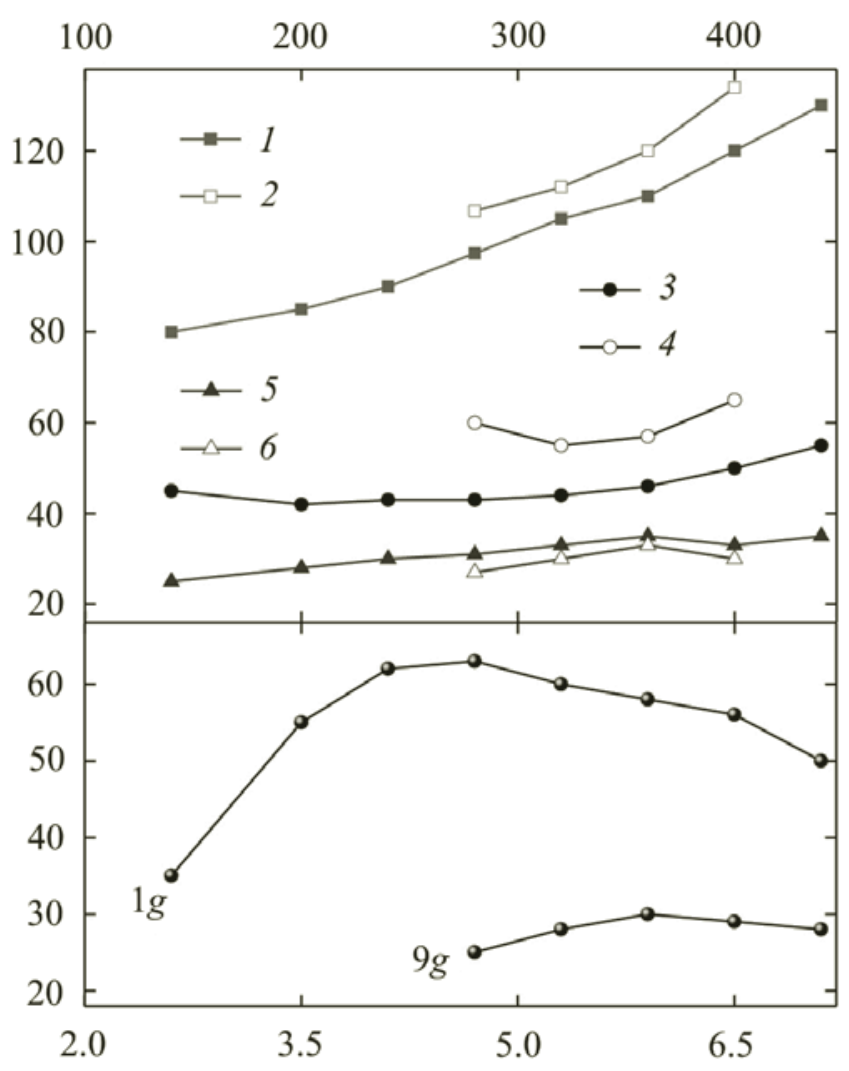

$b$

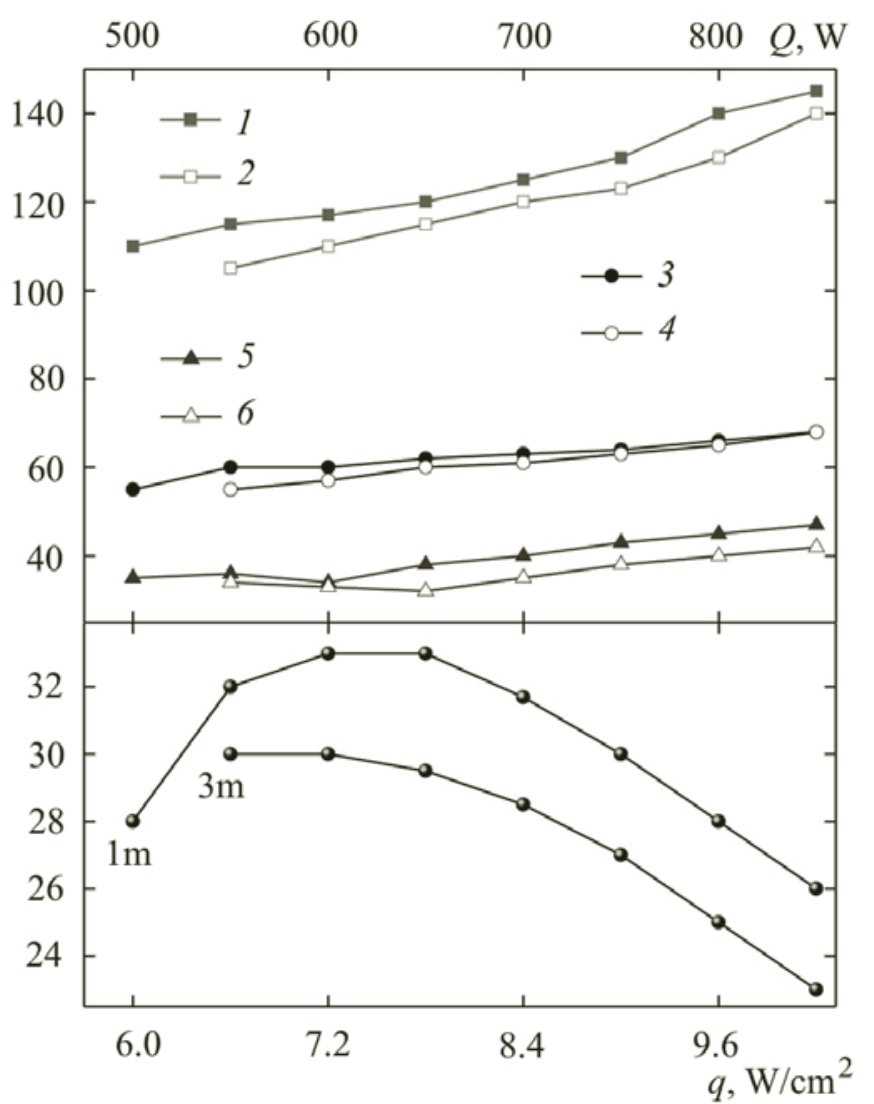

Fig. 6. Dependences of the heater temperature $(1,2)$, the temperature of the liquid at the ejector exit $(3,4)$, and the temperature of the liquid at the evaporator inlet $(5,6)$ in ELHPI No. 1 with a titanium wick at $w=1 g(1,3,5)$ and $9 g(2,4,6)($ a) and in ELHPI No. 2 with a nickel wick at $D=1(1,3,5)$ and $3 \mathrm{~m}(2,4,6)(\mathrm{b})$ and their ejection coefficient $U$ on the power density of the heat flow in them and their heat load.
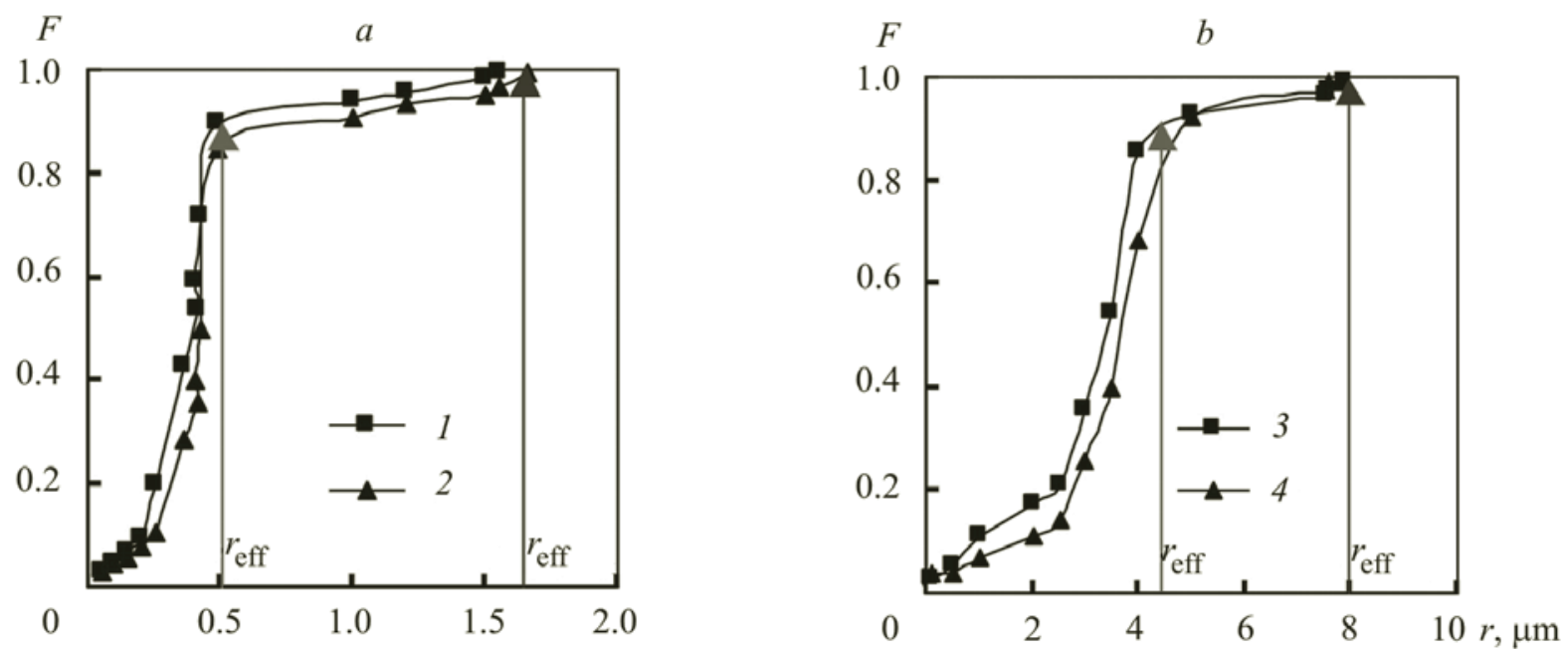

Fig. 7. Integral pore-size distribution function $F(r)$, measured by a mercurial pore meter for the nickel (a) and titanium (b) wicks at $\Pi_{b}=0.66$ (1), 0.61 (2), 0.54 (3) and 0.58 (4). 


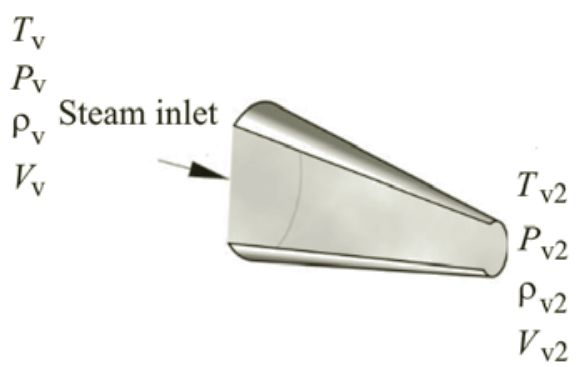

Fig. 8. Isentropic flow of a perfect gas through a convergent nozzle.

and the capillary pressure in the LHPE in the process of its operation is determined by the expression

$$
\Delta P_{\sigma}=\beta \frac{2 \sigma\left(T_{\mathrm{v}}\right)}{r_{\mathrm{eff}}}=\Delta P_{\mathrm{ex}}+\Delta P_{\mathrm{in}}, \quad \beta=\frac{r_{\mathrm{eff}}}{r_{\mathrm{men}}} \leq 1
$$

where $r_{\text {eff }}$ is the effective radius of the largest pores in the CS, and $r_{\text {men }}$ is the radius of the menisci evaporating in the capillary structure of the ELHP. The integral function of the size distribution of pores in this structure is presented in Fig. 7. The value of $r_{\text {eff }}$ can be determined by the air bubble method and by the known pore distribution function; the difference between the results obtained in these ways usually does not exceed $10 \%$. The parameter $\beta$ in (2) ranges from 0 to 1 , and it represents a physical estimate of the degree to which the pumping potential of the indicated menisci is used. When the maximum transport performance of the loop is achieved, $\beta=1$. A further loading of the system leads to the penetration of menisci to the CS bulk and, consequently, to the movement of steam to the liquid core, with the result that the LHPE ceases to operate. In this case, $\beta=0.75$ at a nominal heat load at the inlet of an ELHP.

We consider a model capillary pump representing a region of a wick saturated with a liquid in which the menisci serve as pumping elements. A pressure drop in the porous structure of the wick is considered as its internal pressure loss $\Delta P_{\text {in }}$, and the other pressure losses of the loop form its external pressure loss $\Delta P_{\text {ex }}$. A set of large pores in the upper part of the wick provide comfortable hydraulic conditions for the exhaustion of steam, and they serve as minicollectors of steam at the steam outlet. Therefore, we consider this part of the hydraulic drop $\Delta P_{\mathrm{CS}, \mathrm{v}}$ as a component of the external pressure loss. The pressure-drop components are determined by the expressions

$$
\begin{gathered}
\Delta P_{\mathrm{ex}}=\Delta P_{\mathrm{v}}\left(T_{\mathrm{v}}, \mathrm{M}\right)+\Delta P_{\mathrm{CS}, \mathrm{v}}+\Delta P_{\text {liq }} \pm \Delta P_{\mathrm{h}}, \\
\Delta P_{\text {in }}=\Delta P_{\mathrm{CS}, \text { liq }},
\end{gathered}
$$

where $\Delta P_{\mathrm{v}}\left(T_{\mathrm{v}}, \mathrm{M}\right)$ is the pressure drop in the steam nozzle, $\Delta P_{\mathrm{CS}, \mathrm{v}}$ is the steam pressure drop in the two-phase zone formed by the evaporating menisci in the collector pores of the $\mathrm{CS}, \Delta P_{\text {liq }}$ is the pressure drop in the liquid transport line, $\Delta P_{\mathrm{h}}$ is the hydrostatic pressure drop, and $\Delta P_{\mathrm{CS} \text {,liq }}$ is the liquid pressure drop in the small pores of the CS.

The basic pressure drop in the steam channels of an ELHP is due to the pressure drop in its steam nozzle, where the motive fluid is accelerated to a sonic velocity representing a sound limit of the heat transfer capacity of the ELHP. The pressure drop in the steam nozzle of the ELHP and its components at the nozzle exit (Fig. 8) are determined by the expressions

$$
\begin{aligned}
& \Delta P_{\mathrm{v}}\left(T_{\mathrm{v}}, \mathrm{M}\right)=P_{\mathrm{v}}\left(T_{\mathrm{v}}\right)-P_{\mathrm{v} 2}\left(T_{\mathrm{v}}, \mathrm{M}\right), \quad P_{\mathrm{v} 2}\left(T_{\mathrm{v}}, \mathrm{M}\right)=P_{\mathrm{v}}\left(T_{\mathrm{v}}\right)\left[1+\frac{(k-1) \mathrm{M}^{2}}{2}\right]^{\frac{k}{1-k}}, \\
& T_{\mathrm{v} 2}\left(T_{\mathrm{v}}, \mathrm{M}\right)=T_{v}\left[1+\frac{(k-1) \mathrm{M}^{2}}{2}\right]^{-1}, \quad \rho_{\mathrm{v} 2}\left(T_{\mathrm{v}}, \mathrm{M}\right)=\rho_{\mathrm{v}}\left(T_{\mathrm{v}}\right)\left[1+\frac{(k-1) \mathrm{M}^{2}}{2}\right]^{\frac{1}{1-k}},
\end{aligned}
$$




$$
V_{\mathrm{v} 2}\left(T_{\mathrm{v}}, \mathrm{M}\right)=\sqrt{2 \frac{k}{k-1} \frac{P_{\mathrm{v}}\left(T_{\mathrm{v}}\right)}{\rho_{\mathrm{v}}\left(T_{\mathrm{v}}\right)}\left[1-\left(\frac{P_{\mathrm{v} 2}\left(T_{\mathrm{v}}, \mathrm{M}\right)}{P_{\mathrm{v}}\left(T_{\mathrm{v}}\right)}\right)\right]^{\frac{k-1}{k}}}, \quad C\left(T_{\mathrm{v}}\right)=\sqrt{k R \frac{T_{\mathrm{v}}}{\mu}} .
$$

The rate of the steam mass flow at the exit of the steam nozzle $\dot{m}_{\mathrm{v} 2}\left(T_{\mathrm{v}}, \mathrm{M}\right)$ and its critical heat load $Q_{\mathrm{cr}}\left(T_{\mathrm{v}}, \mathrm{M}\right)$ are determined by the relations

$$
\dot{m}_{\mathrm{v} 2}\left(T_{\mathrm{v}}, \mathrm{M}\right)=\rho_{\mathrm{v} 2}\left(T_{\mathrm{v}}, \mathrm{M}\right) V_{\mathrm{v} 2}\left(T_{\mathrm{v}}, \mathrm{M}\right) \pi \frac{d^{2}}{4}, \quad Q_{\mathrm{cr}}\left(T_{\mathrm{v}}, \mathrm{M}\right)=\dot{m}_{\mathrm{v} 2}\left(T_{\mathrm{v}}, \mathrm{M}\right) h_{\mathrm{liq}, \mathrm{v}}\left(T_{\mathrm{v}}\right)
$$

At $\mathrm{M}=1$ (the sound limit of the LHPE), $Q_{\mathrm{cr}}^{\max }\left(T_{\mathrm{v}}, 1\right)=\dot{m}_{\mathrm{v} 2}\left(T_{\mathrm{v}}, 1\right) h_{\text {liq, } \mathrm{v}}\left(T_{\mathrm{v}}\right)$. The pressure drop in the laminar flow of the liquid in its transport line in the ELHP is defined as

$$
\Delta P_{\text {liq }}=D(U) Q, \quad D(U)=\frac{128}{\pi} \frac{\eta_{\text {liq }}\left(T_{l}\right) U}{\rho_{\text {liq }}\left(T_{\text {liq }}\right) h_{\text {liq, },}\left(T_{\mathrm{v}}\right)} \frac{L_{\text {eff,liq }}}{d_{\text {liq }}^{4}}
$$

The gravitational acceleration of the liquid flow is determined from the expression

$$
\Delta P_{\mathrm{h}}= \pm\left(\rho_{\text {liq }}\left(T_{\text {liq }}\right)-\rho_{\mathrm{v}}\left(T_{\mathrm{v}}\right)\right) H n g
$$

where $n$ is the dimensionless acceleration coefficient (micro- or macrogravity) and $H$ is the height of the liquid and steam layers on the primary evaporation surface of the evaporator in the loop.

The hydraulic losses in the liquid in the CS, making a significant contribution into the pressure drop balance of the ELHP, are determined by the Darcy law with the use of the permeability coefficient $K$ depending on the effective radius of the CS pores $r_{\text {eff }}$. The functional dependence between $K$ and $r_{\text {eff }}$ was determined on the basis of experimental data obtained for different wicks made of sintered metal powders. The parabolic dependences constructed coincide with a standard deviation of $6 \%$. Thus, the permeability of the liquid in the CS can be defined as

$$
K_{\text {liq }}=K_{0} r_{\text {eff }}^{2}, \quad K_{0}=\frac{\Pi_{\mathrm{b}}}{18},
$$

where $K_{0} \approx 0.035$ for the small pores of radius $r_{\text {eff }}=0.5-15 \mu \mathrm{m}$, and $\Pi_{\mathrm{b}}=0.55-0.75$. The effective pore radius $r_{\mathrm{eff}}$ determines the difference between the small and large pores in a wick, as illustrated in Fig. 7 where the pore size distributions measured by a mercurial pore meter for the wicks being considered are presented. It is assumed that the small pores of radius smaller than $r_{\text {eff }}$ belong to the liquid phase, and the large pores of radius larger than $r_{\text {eff }}$ belong to the gas phase. In this case, the permeability of the gas phase in the CS is determined by the relation

$$
K_{\mathrm{v}}=\frac{\Pi\left(r_{\mathrm{eff}, \max }\right)-\Pi\left(r_{\mathrm{men}}\right)}{\Pi\left(r_{\mathrm{eff}, \max }\right)} K_{0} r_{\mathrm{eff}, \max }^{2}
$$

which is true for the values of $r_{\text {men }}$ changing within the range $r_{\text {eff }} \leq r_{\text {men }} \leq r_{\text {eff,max }}$. As $r_{\text {men }}$ approaches $r_{\text {eff, }}, K_{\mathrm{V}}$ reaches its maximum, and $K_{\mathrm{v}}=0$ at $r_{\text {men }}>r_{\text {eff,max }}$. The porosity of the CS is determined by the radius of its pores: $\Pi(r)=\Pi_{\mathrm{b}} \varphi(r)$. From this equation follows the expressions $\Pi\left(r_{\text {eff,max }}\right)=\Pi_{\mathrm{b}}$ and $\Pi_{\text {liq,p }}=\Pi\left(r_{\text {men }}\right)-\Pi\left(r_{\text {eff }}\right)$.

With the above definitions, we represent a pressure drop in the CS as a function of its heat load $Q$. For the liquid phase we have the expression

$$
\Delta P_{\mathrm{CS}, \mathrm{liq}}=\frac{B_{\mathrm{liq}}}{r_{\mathrm{eff}}^{2}} Q
$$

The coefficient $B_{\text {liq }}$ depends on the CS geometry and, for the cylindrical geometry, it is defined as 

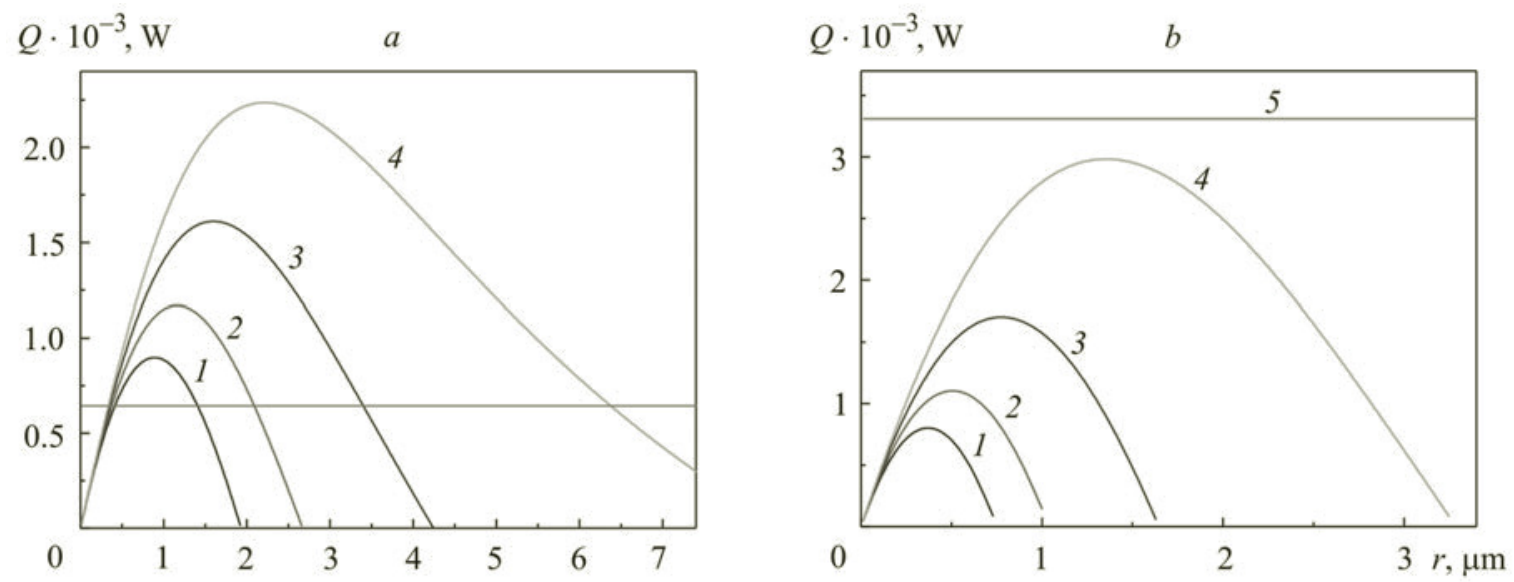

Fig. 9. Comparison of the sound and hydrodynamic limits of a water ELHP (a) and a methanol ELHP (b) at $\mathrm{M}=1.0(1), 0.8(2), 0.6(3)$, and 0.4 (4): 5) $Q_{\mathrm{cr}}^{\max }$.

$$
B_{\text {liq }}=\frac{1}{2 \pi K_{0}} \frac{\eta_{\text {liq }}\left(T_{\mathrm{v}}\right)}{h_{\text {liq, },}\left(T_{\mathrm{v}}\right) \rho_{\text {liq }}\left(T_{\mathrm{v}}\right)} \frac{1}{l_{\text {inp }}} \ln \left(\frac{d_{\mathrm{CS}, \mathrm{ex}}}{d_{\mathrm{CS}, \text { in }}}\right) .
$$

The pressure drop in the gas phase in the CS is determined from the expression

$$
\begin{gathered}
\Delta P_{\mathrm{CS}, \mathrm{v}}=\frac{B_{\mathrm{v}}}{r_{\mathrm{eff}, \max }^{2}} Q, \\
B_{\mathrm{v}}=\frac{\Pi_{\mathrm{b}}}{K_{0} \Pi_{\text {liq,p }}} \frac{\eta_{\mathrm{v}}\left(\mathrm{T}_{\mathrm{v}}\right)}{\rho_{\mathrm{v}}\left(\mathrm{T}_{\mathrm{v}}\right) h_{\text {liq, }}\left(\mathrm{T}_{\mathrm{v}}\right)} \frac{l_{\mathrm{eff}} \xi}{A_{\text {inp }}},
\end{gathered}
$$

where $\xi>1$ is a coefficient determining the decrease in the cross section of the CS in the zone of the steam grooves: $\xi=A_{\text {inp }} /\left(A_{\text {inp }}-A_{\mathrm{v}, \mathrm{g}}\right), A_{\text {inp }}$ is the heat input area, and $A_{\mathrm{v}, \mathrm{g}}$ is the total cross-sectional area of the steam grooves. In the case where $r_{\text {men }}>r_{\text {eff,max }}, B_{\mathrm{v}}=0$.

Of great importance for an evaporating system with "inverted menisci" is the presence of large pores in it and the number of these pores. On the one hand, an increase in the number of large pores in a wick of an ELHP increases the probability of the breakthrough of team through it, which disturbs the operation of the ELHP, and on the other this increase is favorable for collection of steam. The effective length of a steam flow in the two-phase zone of the CS of the ELHP was determined by the experimental dependence

$$
l_{\text {eff }}=(8, \ldots, 10) r_{\text {eff }} \psi,
$$

where $\psi$ is the tortuosity of the pores determined experimentally, and $\psi=4-6$ for the CS used in the present work. Substitution of (16) into (15) and then substitution of the expression obtained into (3) give

$$
\Delta P_{\mathrm{ex}}=\left(\frac{B_{\mathrm{v}}}{r_{\mathrm{eff}, \max }^{2}}+D\right) Q+\Delta P_{\mathrm{h}}+\Delta P_{\mathrm{v}} .
$$

As a result of the solution of Eqs. (2)-(17), we obtained the relation for the heat load

$$
Q(r, \mathrm{M}, U)=\frac{\beta 2 \sigma\left(T_{\mathrm{v}}\right) r_{\mathrm{eff}}-\left[\Delta P_{\mathrm{h}}+\Delta P_{\mathrm{v}}\left(T_{\mathrm{v}}, \mathrm{M}\right)\right] r_{\mathrm{eff}}^{2}}{\left(\frac{B_{\mathrm{v}}}{r_{\mathrm{eff}, \max }^{2}}+D(U)\right) r_{\mathrm{eff}}^{2}+B_{\mathrm{liq}}} .
$$


Formula (18) gives the hydrodynamic limit of the ELHP.

Figure 9 presents results of calculations of an ELHP with parameters given in Fig. 2. The data obtained show that a water ELHP reaches a sound limit earlier than the hydrodynamic one, and the opposite is true for a methanol ELHP, which is well consistent with the experimental data presented in Fig. 6.

Discussion. Aanalysis of the experimental data obtained shows that the problem on substantial increase in the distance between the source and heat receivers (the heat transfer distance) in an ELHP without significant loss in its heat transfer efficiency can be solved by increasing the ejection coefficient of the ELHP $(U>1$, Fig. 2$)$.

Actually, in an ELHP, having an unfavorable orientation $\left(\varphi=90^{\circ}\right)$, with a single circulation flow $(U=1)$, the evaporation-condensation region along the heat transfer distance is divided by an uncompensated liquid column with a maximum hydrostatic pressure. An increase in the heat transfer distance in the ELHP leads to an increase in the hydrostatic pressure in the liquid column, with the result that the capillary action of the ELHP wick, causing the working liquid to move, sharply decreases, which leads to a substantial decrease in the heat transfer in the ELHP.

In an ELHP with a multiple circulation $(U>1)$, condensation takes place in the close proximity to the evaporation, while the region of evaporation and heat removal is divided by a liquid circulation loop of length sufficient for realization of heat transfer. In particular, at $\varphi=90^{\circ}$, the uncompensated liquid column is insignificant in comparison with the heat transfer distance, Therefore, this distance can be substantially increased without a risk of large increase in the resistance of the circulation loop to the liquid flow. As follows from Fig. 6b, a threefold increase in the heat transfer distance causes insignificant changes in the operational characteristics of ELHPI No. 2, markedly decreases its ejection coefficient, and increases the minimum heat load $Q$ to the value sufficient for the start-up of the ejector. The effects of increasing the unfavorable acceleration of the liquid flow in ELHP increase the heat transfer distance in it.

An ELHP with a large injection coefficient $(U>15-20)$ is more suitable for the use in practice, e. g., in the cooling of heat sources by liquid. Heat sources and sinks each with a capacity not higher than that of the main heat source in the evaporator of the ELHP are positioned in series along its circulation loop. The number and total capacity of these heat sources and sinks are limited by the heat transfer capacity of the ELHP. In a series of experiments, ELHPI No. 2 was supplemented with a flat electronic circuit board and an additional heat exchanger. The working liquid flowed through the grooves in the inner cavity of the board. Experiments have shown that, at an evaporator heat load $Q=300-600 \mathrm{~W}$, an ejection coefficient $U=10-40$, and a circuit board temperature of $50^{\circ} \mathrm{C}$, the circulating liquid can take off heat loads as high as $150 \mathrm{~W}$ from the plane electronic plate, which allows the conclusion that such a ELHP can be used as a part of distributed thermal control systems in devices operating under space and earth conditions.

Conclusions. The possibility of using loop heat pipes with an ejector condenser in cooling systems with an increased heat transfer distance, operating under unfavorable conditions where the use of other heat pipes can be problematic, has been demonstrated for the first time. The experimental data obtained for different ELHPs show that they have a high resistance to the effects of unfavorable acceleration of the liquid flow in them, make it possible to construct thermal control systems with temperature pickups at any spatial points, provide a relatively high heat energy density (as high as $100 \mathrm{~kW} / \mathrm{m}^{2}$ ) in combination with a low thermal resistance (about $0.1 \mathrm{~K} / \mathrm{W}$ ) in the operation under conditions not suitable for other heat pipes, and are difficult to startup at high temperatures (about $50^{\circ} \mathrm{C}$ ), in particular, in the heated state immediately after the stop because of the insufficient condensation of the steam jet in the ejector condencer. The results of calculations performed by the model developed agree well with the corresponding experimental data.

Acknowledgment. The authors express their gratitude to the Ministry of Education and Science of the Russian Federation for support of their work within the framework of the State Task for Higher Educational Institutions (Project FEUZ-2020-0057).

\section{NOTATION}

$c$, specific heat, $\mathrm{J} / \mathrm{kg} / \mathrm{K} ; C$, velocity of sound, $\mathrm{m} / \mathrm{s} ; D$, effective heat transfer distance, $\mathrm{m} ; d$, steam nozzle outlet diameter, $\mathrm{m} ; g$, gravitational acceleration, $\mathrm{m} / \mathrm{s}^{2} ; H$, height of the liquid and steam layers in an ELHP, $\mathrm{m} ; h_{\mathrm{liq}, \mathrm{v}}$, specific latent heat, $\mathrm{J} / \mathrm{kg} ; k$, adiabatic constant; $L$, length of the ELHP, m; M, Mach number; $\dot{m}$, mass flow rate, $\mathrm{kg} / \mathrm{s} ; P$, pressure, $\mathrm{Pa} ; Q$, heat load, $\mathrm{W} ; q$, heat flow, $\mathrm{W} / \mathrm{m}^{2} ; R$, universal gas constant, $\mathrm{J} / \mathrm{mole} / \mathrm{K} ; T$, temperature, ${ }^{\circ} \mathrm{C}, \mathrm{K} ; U$, ejection coefficient; $V$, velocity of a steam jet, $\mathrm{m} / \mathrm{s} ; w$, acceleration of the liquid flow, $\mathrm{m} / \mathrm{s}^{2} ; \eta$, dynamic viscosity, $\mathrm{m}^{2} / \mathrm{s} ; \mu$, molar mass, mole; $\Pi_{\mathrm{b}}$, bulk porosity of the capillary structure; $\sigma$, coefficient of surface tension, $\mathrm{N} / \mathrm{m} ; \varphi$, angle of inclination of the ELHP about the horizontal, deg. Subscripts: amb, ambient; b, bulk; h, hydraulic; cr, critical; c.w, cooling water; ex, external; g, groove; in, internal; inp, input; out, output; liq, liquid; $p$, pore; v, vapor. 


\section{REFERENCES}

1. A. Shah, I. R. Chughtai, and M. H. Inayat, Experimental study of the characteristics of steam jet pump and effect of mixing section length on direct-contact condensation, Int. J. Heat Mass Transf., 58, 62-69 (2013)

2. M. W. Wu and L. Y. Zhang, Compressor with Vapor Injection System, USA Patent No. 8037710 B2, published on October 18, 2011.

3. J. Yan, S. Shao, J. Liu, and Z. Zhang, Experiment and analysis on performance of steam-driven jet injector for districtheating system, Appl. Therm. Eng., 25, 1153-1167 (2005).

4. H. S. Aybar and N. Beithou, Passive core injection system with steam driven jet pump for next generation nuclear reactors, Ann. Nucl. Energ., 26, 769-781 (1999).

5. G. Cattadori, L. Galbiati, L. Mazzocchi, and P. Vanini, A single-stage high pressure steam injector for next generation reactors: Test results and analysis, Int. J. Multiph. Flow, 21, 591-606 (1995).

6. P. Dumaz, G. Geffraye, V. Kalitvianski, E. Verloo, M. Valisi, P. Meloni, A. Achilli, R. Schilling, M. Malacka, and M. Trela, The DEEPSSI project, design, testing and modeling of steam injectors, Nucl. Eng. Des., 235, 233-251 (2005).

7. T. Narabayashi, W. Mizumachi, and M. Mori, Study on two-phase flow dynamics in steam injectors, Nucl. Eng. Des., 175, 147-156 (1997).

8. T. Narabayashi, S. Ohmori, M. Mori, Y. Asanuma, and C. Iwaki, Development of multi-stage steam injector for feedwater heaters in simplified nuclear power plant, JSME Int. J. B - Fluid T, 49, 368-376 (2006).

9. S. Ohmori, T. Narabayashi, and M. Mori, Scale model test and transient analysis of steam injector driven passive core injection system for innovative-simplified nuclear power plant, J. Power Energy Syst., 2, 492-500 (2008).

10. X. Xu, Investigation of Vapor Injection Heat Pump System with a Flash Tank Utilising $R 410 A$ and Low-GVP Refrigerant R32, Ph.D. Thesis, University of Maryland, USA (2012).

11. Yu. Gerasimov, Yu. Maidanik, Yu. Dolgirev, and V. Kiseev, Some results of investigation of low-temperature heat pipes operating against gravity field, Zh. Inzh. Fiz., 30, 581-586 (1976)

12. Yu. F. Maydanik, Loop heat pipes, Appl. Therm. Eng., 25, 635-657 (2005).

13. V. M. Kiseev, N. P. Pogorelov, and V. A. Nouroutdinov, Modeling and Experimental Investigating Loop Heat Pipes, Amer. Inst. of Chem. Eng., New York (1995).

14. V. M. Kiseev, V. V. Vlassov, and I. Muraoka, Experimental optimization of capillary structures for loop heat pipes and heat switches, Appl. Therm. Eng., 30, 1312-1319 (2010).

15. V. M. Kiseev, V. V. Vlassov, and I. Muraoka, Optimization of capillary structures for inverted meniscus evaporators of loop heat pipes and heat switches, Int. J. Heat Mass Transf., 53, 2143-2148 (2010).

16. V. M. Kiseev, N. P. Pogorelov, and L. I. Menkin, The study on two-phase thermosyphon application for mock-up fuel elements temperature regime modelling, in: Proc. 8th Int. Heat Pipe Conf., Beijing, China, 1992, pp. 673-678.

17. Th. D. Swanson and G. C. Birur, NASA thermal control technologies for robotic spacecraft, Appl. Therm. Eng., 23, 1055-1065 (2003).

18. V. Antonov, M. Balykin, A. Golikov, K. Goncharov, K. Korzhov, and V. Buz, Designing and analysis of precise thermal control system with loop heat pipe, in: Proc. 2th Int. Conf. "Heat Pipes for Space Application," Khimky, Russia, 2014, pp. $1-15$.

19. V. Kissev, D. Aminev, and V. Cherkashin, Two-phase systems for light-emitting diodes cooling, Heat Pipe Sci. Technol., 2, 121-131 (2011).

20. Yu. Gerasimov, V. Kiseev, Yu. Maidanik, and Yu. Dolgirev, Low-temperature heat pipes with vapour injection, J. Eng. Phys., 33, 573-580 (1977).

21. V. M. Kiseev, Yu. F. Maidanik, and Yu. F. Gerasimov, Heat-Transporting Device, USA Patent No. 4467861 A, published on August 28, 1984. 